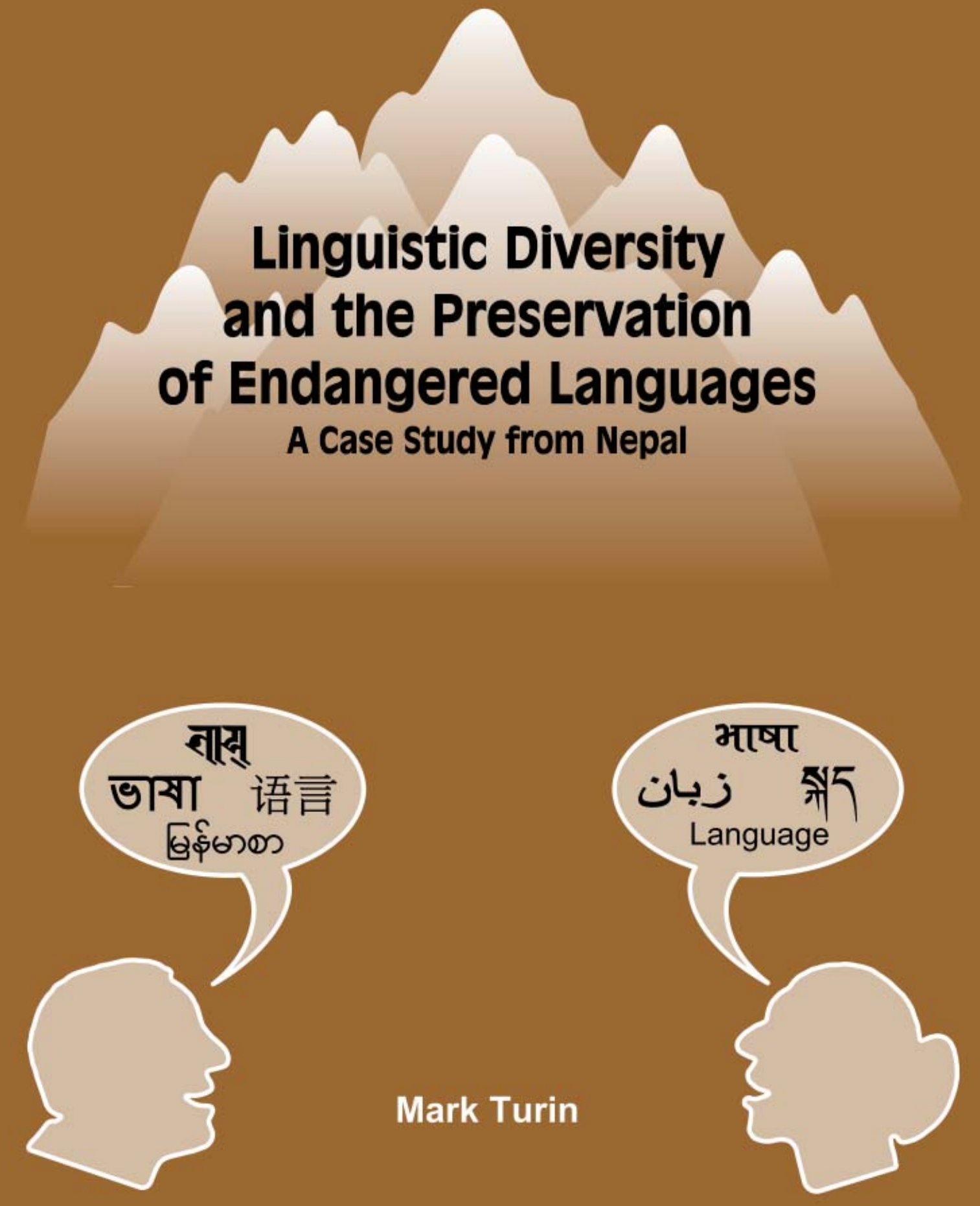




\section{About ICIMOD}

The International Centre for Integrated Mountain Development (ICIMOD) is an independent 'Mountain Learning and Knowledge Centre' serving the eight countries

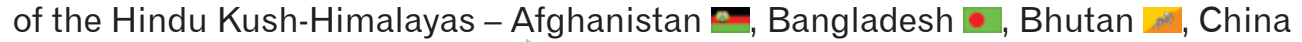

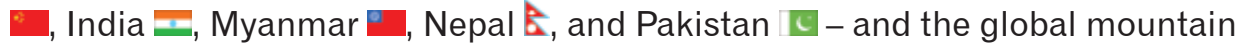
community. Founded in 1983, ICIMOD is based in Kathmandu, Nepal, and brings together a partnership of regional member countries, partner institutions, and donors with a commitment for development action to secure a better future for the people and environment of the extended Himalayan region. ICIMOD's activities are supported by its core programme donors: the governments of Austria, Denmark, Germany, Netherlands, Norway, Switzerland, and its regional member countries, along with over thirty project co-financing donors. The primary objective of the Centre is to promote the development of an economically and environmentally sound mountain ecosystem and to improve the living standards of mountain populations.

The 'Talking Points' series from ICIMOD contains short presentations of topical, controversial, or problematic themes, where general consensus has not yet been reached or where action may be appropriate. They are intended to stimulate thought, and discussion, their contents should not be seen as definitive statements. 


\section{Linguistic Diversity \\ and the Preservation of \\ Endangered Languages}

A Case Study from Nepal

Mark Turin

International Centre for Integrated Mountain Development (ICIMOD)

Kathmandu, Nepal

December 2007 


\section{Copyright @ 2007}

International Centre for Integrated Mountain Development (ICIMOD)

All rights reserved

\section{Published by}

International Centre for Integrated Mountain Development

G.P.O. Box 3226

Kathmandu, Nepal

\section{ISBN 9789291150557 (printed)}

9789291150748 (electronic)

\section{Production team}

Joyce M. Mendez (Editor)

A. Beatrice Murray (Senior Editor)

Punam Pradhan (Layout Design)

Asha Kaji Thaku (Editorial Assistant)

\section{Printed and bound in Nepal by}

Quality Printers Pvt. Ltd.

Kathmandu

\section{Reproduction}

This publication may be reproduced in whole or in part and in any form for educational or non-profit purposes without special permission from the copyright holder, provided acknowledgement of the source is made. ICIMOD would appreciate receiving a copy of any publication that uses this publication as a source.

No use of this publication may be made for resale or for any other commercial purpose whatsoever without prior permission in writing from ICIMOD.

\section{Note}

The views and interpretations in this publication are those of the author. They are not attributable to ICIMOD and do not imply the expression of any opinion concerning the legal status of any country, territory, city or area of its authorities, or concerning the delimitation of its frontiers or boundaries, or the endorsement of any product.

This publication is available in electronic form at http://books.icimod.org 
Foreword

Acknowledgements

Summary

Acronyms and Abbreviations

Part 1: Setting the Scene

The Greater Himalayan Region: A Language 'Mega Centre'

The Linguistic Wealth of Nepal

The Status of Nepal's Endangered Languages 5

Preserving and Promoting Linguistic Diversity in the Himalayan Region 10

Part 2: The Position of Language in Nepal's Bio-cultural Context 13

Language and Ecology: An Intimate Symbiosis

Language and the Constitution: Promise versus Delivery

Language and the Law: Linguistic Advocacy and Municipal Debate

Language and the Census: Who is Being Counted and Why?

Language and Media: Nepal's Minority Voices on Air and in Print

Language and Education: the Mother Tongue Debate

Language and Gender: the Central Role of Women

Language and Conflict: Maoists, Politics, and Sanskrit

Language and Culture: Identity in Difference

Part 3: Sustainable Futures: Promotion of Diversity at all Levels 29

Language Policy in Neighbouring Himalayan States

Signs of Hope: Projects Underway in Nepal and the Himalayas 


\section{Foreword}

Mountains in general and the Himalayas in particular are not only centres of extraordinary biodiversity, they are also cultural and linguistic hotspots. Of the approximately 600 languages found in the Himalayas, over 400 are spoken by groups of less than 100,000 people, and most of these are in danger of extinction. Analogous to the threat of species extinction, the extinction of languages should be regarded as an unrecoverable loss of diversity for all of humankind.

Since its foundation in 1983, ICIMOD has supported the livelihoods of mountain peoples in various ways. The Centre helps to create sustainable mountain societies by promoting an enabling environment that enhances equity and empowers marginalised mountain people in the Hindu Kush-Himalayas. This includes the preservation and promotion of the existing social, cultural and linguistic diversity as the basis of human well-being.

Mark Turin, the author of this publication, brings together a wide range of information on language diversity, endangerment, and preservation, and situates these debates in the social context of contemporary Nepal. His findings clearly illustrate the interrelatedness of language, culture, knowledge, and ethnicity, as well as the close connection with questions of minorities, political orientation, and even ecological sustainability.

A disturbingly large number of Nepal's over 100 mother tongues are severely endangered and will likely be reduced to symbolic identity markers within a generation. At the same time, we can observe a revival of ethnic identities often closely related to linguistic attributes.

The lessons drawn from this study reach far beyond the Nepali context and may be applied to other multilingual societies across the Himalayan region and worldwide. Successful efforts to keep languages from extinction ideally combine mother tongue literacy and education with improvements in the socioeconomic and political status of minority language communities.

This publication demonstrates that cultural diversity, a characteristic feature of mountain regions, is an important asset for sustainable development. Given the high level of current interest in ethnolinguistic issues in Nepal, we hope that this publication will contribute to further policy developments which acknowledge that cultural and linguistic diversity enrich society.

Michael Kollmair

Culture, Equity, Gender and

Governance Programme

ICIMOD 


\section{Acknowledgements}

I would like to thank the staff of ICIMOD and in particular the former Director General, J. Gabriel Campbell, for providing me this unique opportunity to write about linguistic diversity and language endangerment in Nepal. The last few years of Nepal's political trajectory have been tumultuous, and linguistic rights have received a great deal of attention within general discussions of social inclusion. Writing about these topics has been rather like playing chess on a constantly moving board, so framing such ideas and committing them to paper has taken considerable time. I am grateful for the patience, support, and flexibility that ICIMOD has afforded me.

The Culture, Equity, Gender and Governance (CEGG) programme has been my institutional home during my tenure as a visiting scientist at ICIMOD, and I could not have hoped for a more supportive and like-minded group of colleagues. Special thanks must go to Anupam Bhatia, the then Programme Manager of CEGG, whose enthusiasm brought me on board and who has long been interested in exploring the interconnections between linguistic diversity and biodiversity. Anupam's successor as Programme Manager, Michael Kollmair, has continued in the spirit of CEGG: intellectually rigorous, dynamic and deeply committed to enhancing equity and empowering marginalised mountain people. It continues to be a pleasure to work with him and to have had the present Talking Points shepherded through the production pipeline with his care and attention. I thank him for his support and trust.

It would be impossible to name all the people at ICIMOD who have helped to make my time there enjoyable, but a few deserve special mention. Within CEGG, I continue to enjoy discussions about the passions that we share with Nani R. Subedi, Krishna Prasad Oli, Joy Dasgupta, and Radhika Gupta. Without the patience of Govinda Shrestha, I would have been lost, and I thank him for his ever-ready help. A. Beatrice Murray, C.N. Anil, Prativa Chhetri, Jenny Vaidya, Milan Raj Tuladhar, and the amazing Saisab Pradhan have all helped in countless ways to make ICIMOD a colourful and dynamic place to work. Thank you. Special thanks also to Joyce M. Mendez, my editor, for her ongoing support during the production of the book, and to Punam Pradhan for the layout and for patiently overseeing numerous corrections to the maps.

Policy papers such as this rely on a large corpus of freely available data which has been carefully collected and compiled by individual researchers or organisations. In particular, I am grateful to the editors of the online Ethnologue, staff at the Central Bureau of Statistics, and designers and developers at the ICIMOD MENRIS Division for providing open-access resources to facilitate comparative analysis.

I have also benefited from helpful comments made by Yogendra Prasad Yadava, Professor at the Central Department of Linguistics at Tribhuvan University. His attention to detail and critical engagement with my work are truly appreciated. Finally, I should like to spare a word for Mark Flummerfelt and Sara Shneiderman, both of whom have read drafts of this document and offered valuable and constructive criticism. Needless to say, I take full responsibility for any errors, oversights, or historical inaccuracies which may have crept in, and for any important omissions which may have crept out. 


\section{Summary}

This discussion paper aims to situate language in its social context, specifically within Nepal, but also across the greater Himalayan region in general. Language rights and access to education in one's mother tongue are fundamental aspects of sustainable livelihoods, all the more so when the languages and communities who speak them are under threat. This issue of Talking Points locates the growing debate about linguistic diversity and the preservation, promotion, and protection of endangered mother tongues within a wider discussion of culture, equity, gender, and governance.

According to even the most conservative estimates, at least half of the world's 6,500 languages are expected to become extinct in the next century. While the documentation of endangered languages has traditionally been the domain of academic linguists and anthropologists, international awareness about this impending linguistic catastrophe is growing, and development organisations are becoming involved in the struggle to preserve spoken forms. The death of a language marks the loss of yet another piece of cultural uniqueness from the mosaic of our diverse planet, and is therefore a tragedy for the heritage of all humanity.

Language death is often compared to species extinction, and the same metaphors of preservation and diversity can be invoked to canvas support for both biodiversity and language preservation programmes. In this sometimes provocative document, I present the options and challenges for linguistic development in the greater Himalayan region.

This issue of Talking Points is intended to be a discussion paper, drawing on publicly available data together with some contextual analysis. I begin by discussing the linguistic diversity of Nepal in the frame of wider debates about diversity of all forms, and move on to situate language in the context of ecology, the state, the legal system, the national census, the media, the education sector, gender, the Maoist insurgency, and, finally, culture. The last section is devoted to comparative examples from other states in the greater Himalayan region and to an analysis of government institutions and non-government organisations which already are, or may be willing to, support linguistic projects in Nepal. Throughout, I aim to position language in the context of wider social and cultural issues.

It is my hope that policy makers may benefit from an increased appreciation of groundlevel realities for understanding the complexity of the ethnolinguistic fabric of modern Nepal, and that scholars will pause for a moment to reflect on the formation and implementation of suitable policy. 


\section{Acronyms and Abbreviations}

NEFIN Nepal Federation of Indigenous Nationalities

NFDIN

National Foundation for Development of Indigenous Nationalities

UNESCO

United Nations Educational, Scientific and Cultural Organization 